\title{
HIGH ACCURACY 3D DIGITISATION OF THE GOETHE ELEPHANT SKULL USING HAND-HELD 3D SCANNING SYSTEMS AND STRUCTURE FROM MOTION - A COMPARATIVE CASE STUDY
}

\author{
P. Kalinowski ${ }^{1}$, K. Füldner ${ }^{2}$, M. Mittmann ${ }^{1}$, A. Schierbaum, ${ }^{1}$ T. Luhmann ${ }^{1}$ \\ ${ }^{1}$ Jade University of Applied Sciences, Institute of Applied Photogrammetry and Geoinformatics (IAPG), Ofener Str. 16/19, D-26121 \\ Oldenburg, Germany - (paul.kalinowski, luhmann)@jade-hs.de, (marcel.mittmann, arne.schierbaum)@student.jade-hs.de \\ ${ }^{2}$ Museum of Natural History Kassel, Steinweg 2, D-34117 Kassel, Germany - kai.fueldner@kassel.de
}

\section{Commission II}

KEY WORDS: Goethe Elephant skull, cultural heritage, colour calibration, SfM, hand-held 3D scanning

\begin{abstract}
:
The Goethe Elephant skull is a cultural object of great interest. For the highly accurate 3D digitisation of the object, a hand-held 3D scanning system (Creaform GO!Scan) and Structure-from-Motion (DSLR camera) were used. The aim is a complete spatial reconstruction with a resolution of $0.5 \mathrm{~mm}$ and an accuracy level of approximate $0.5 \mathrm{~mm}$. The skull consists of three parts, which have very complex but also very simple surface structures. For both methods the data acquisition and processing is described in detail. In both cases, a complete textured meshed 3D model could be calculated without shadows due to the use of camera-fixed lighting. The 3D models fulfil the desired target resolution and accuracy, verified by independent reference lengths and by the manufacturer's specifications. In addition, the colour values of the texture were calibrated with the help of the ColorChecker Digital SG. A visual and geometric comparison of the two models shows that both methods are very well suited for high-precision 3D object reconstruction on a similar level of accuracy. Furthermore, the advantages and disadvantages of the methods are compared. The main advantage of the applied hand-held scanner is the real-time verification of the model during data acquisition. The established SfM convinces with its flexibility regarding resolution and camera positioning.
\end{abstract}

\section{INTRODUCTION}

\subsection{Motivation}

For many cultural objects, there are already automated stations for complete 3D digitisation (Santos et al., 2014). However, for objects that are not easy to transport, on-site acquisition solutions must be developed. One example is given by the Goethe Elephant skeleton from the Museum of Natural History located in the Ottoneum in Kassel, Germany (Figure 1). The skull of the elephant is of greatest historical and scientific interest.

Probably as a gift from Prince William V of Orange to Landgrave Frederick II, an Asian elephant came to Kassel in 1773. With an age of two years, the elephant was still very young. The elephant lived chained up for the most part, but was also used at opera performances or as a working animal. In 1780, the elephant slipped down a steep slope and suffered a fatal skull injury. For the anatomist Samuel Thomas Soemmerring, who taught in Kassel, the death of the young Asian elephant was significant from a scientific point of view. This made it possible to create the probably largest skeletal montage of a large mammal. Johann Wolfgang von Goethe borrowed the skull in 1784 to conduct comparative studies of the intermaxillary bone. Hence the name Goethe Elephant was derived. In that time the alleged absence of the intermaxillary bone in humans was considered to be a distinguishing feature between humans and animals. Goethe was able to prove this bone in humans as well. However, the discussion continued (Matuschek, 2020).

The skull can be described as a complex object due to its size, arbitrary free-form surfaces, small openings, high degree of shadowing and occlusions. A major challenge is to place the object in such a way that it can be recorded from all sides. The aim is to calculate a $3 \mathrm{D}$ model of the elephant skull and achieve a resolution and an accuracy level of $0.5 \mathrm{~mm}$. Due to the sensitive surface, non-contact optical measurement technology is particularly suitable. The data acquisition was carried out with hand-held 3D scanning systems (active method) and Structurefrom-Motion (SfM), both well-established technologies in cultural heritage use cases (Stylianidis \& Remondino, 2016). The final $3 \mathrm{D}$ data is designated for visualisation purposes in virtual environments, and for 3D prints.

This paper presents the data acquisition and evaluation process of the Goethe Elephant skull using SfM and a hand-held 3D scanning system. Both the final 3D models and the application of the photogrammetric methods are evaluated and compared. Advantages and disadvantages of the respective methods are presented.

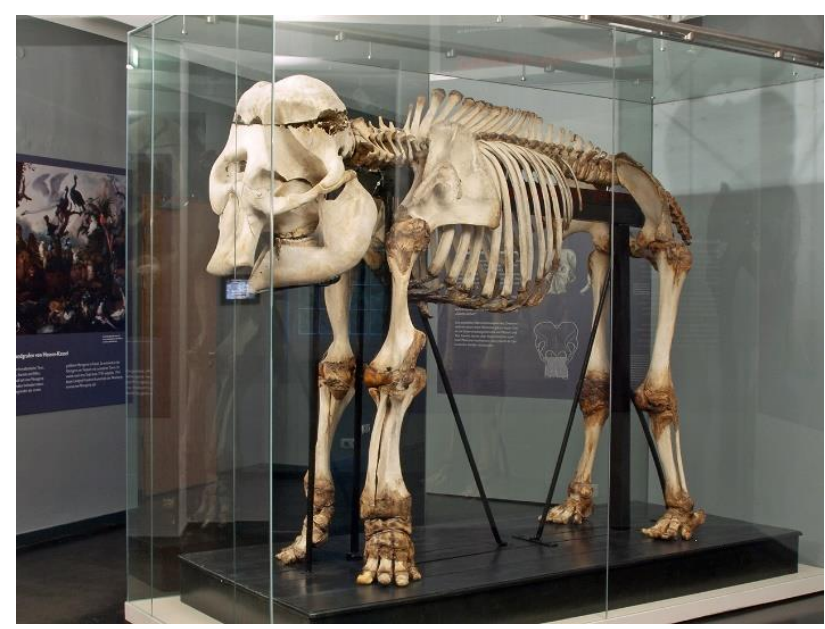

Figure 1. Skeleton of the Goethe Elephant in Kassel (@ Peter Mansfeld, Kassel). 


\subsection{Related Work}

Both hand-held 3D scanning systems and SfM have already been used in various use cases in the field of cultural heritage. For example, de Luca et al. (2019) have used hand-held 3D scanners to record rather small objects that are later 3D printed. One example for SfM applications is given by Fau et al. (2016) for the digitisation of bones of mounted skeletons.

Hand-held scanners as well as SfM applications can be verified to industrial standards such as VDI 2634 (Kersten et al., 2018), (Nietiedt et al., 2020). This generally enables the definition of accuracy requirements for cultural objects according to industrial standards.

The possibilities and limitations of using hand-held scanners and SfM in comparison for the recording and modelling of cultural objects was carried out by Lachat et al. (2017) and Barszcz et al. (2021).

Lachat et al. (2017) investigate the Faro Freestyle3D scanner and identified advantages in this use case due to simple and fast recording and modelling. Barszcz et al. (2021) use the Artec Spider, but in this case the long processing time of the Artec software does not bring any advantages in comparison with SfM. This makes it clear that the practical use strongly depends on which scanner system is used.

\subsection{Goethe Elephant skull}

Even though the skeleton of the elephant is still completely preserved, only the skull has been recorded, which was part of Goethe's research. The elephant skull consists of three individual parts shown in Figure 2. The lower jaw has a size of approx. 60 x $60 \times 40 \mathrm{~cm}$, the upper skull has a size of $60 \times 30 \times 20 \mathrm{~cm}$, and the main skull has a size of $80 \times 60 \times 60 \mathrm{~cm}$. The object surface consists of both simple and very complex structures. On the one hand, the main skull has parts that are occluded (zygomatic arch, maxilla) or very finely structured (cranial suture). Furthermore, there are numerous hollow and inner spaces, such as the eye socket or nasal cavity. These were not focussed on in this work. It might be possible to record them with miniature cameras using macro photogrammetry. On the other hand, there are smooth areas such as the forehead bone. A challenge is that the elephant skull cannot be set up to record it completely. The parts have to be recorded from above and below individually.
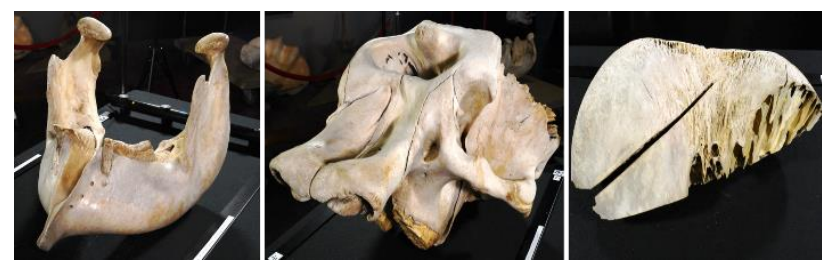

Figure 2. Lower jaw (left) main skull (middle) and upper skull (right) of the Goethe Elephant skull.

\section{DATA ACQUISITION}

The data acquisition was done at the Museum of Natural History Kassel (Figure 4). For both measurement methods, the object was placed on a table to be as accessible as possible. Additional highprecision scale bars were attached to ensure metric scaling. After the object was firstly recorded from one side (top), it was carefully turned around and recorded from the other side (bottom). Thereby it is possible to reconstruct the entire surface of the object without missing information. The data acquisition was carried out in a darkened room without ambient light. Only four LED floodlights with a colour temperature of approx. 5,500 Kelvin (daylight) were used. This ensured a consistent diffuse lighting situation with less reflections and shadows and without extraneous light influences.

For the SfM data acquisition, a black, non-reflective background was used. This enables the masking of the images during data processing (see chapter 3.1).

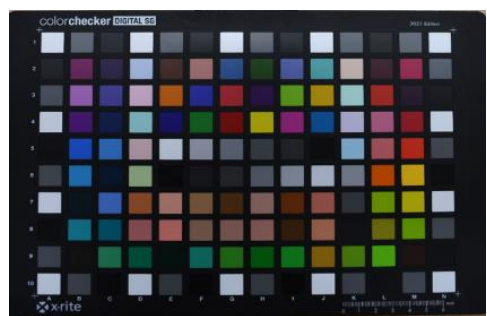

Figure 3. ColorChecker DigitalSG for colour calibration.

When digitising cultural objects, the calibration of the object colour is of high importance. The colour can be calibrated with a colour chart as an independent reference. As recommended by FADGI (2016) and van Dormolen (2012), the ColorChecker Digital SG (Figure 3) from x-rite was used and placed in the measurement volume. For SfM the colour chart was positioned in advance on the spot where the object would later be located. When using the hand-held scanner, the colour chart was recorded together with the object at the same time.

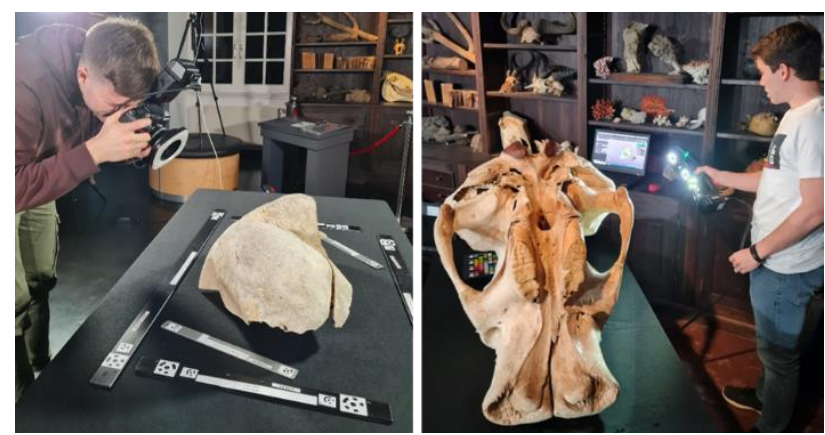

Figure 4. Data acquisition SfM (left) and hand-held scanning system Creafom GO!Scan (right).

\subsection{Structure-from-Motion}

The photogrammetric recording for SfM was carried out using a DSLR Nikon D850 with $24 \mathrm{~mm}$ NIKKOR lens. The specifications of the camera are listed in Table 1. The data acquisition was carried out according to the recommendation of Wenzel et al. (2013) with the aim of complete photogrammetric surface reconstruction. For more complex and potentially shadowed object areas, it is recommended to capture a higher number of images from different viewing angels and with shorter baselines. At less complex object areas, the number of images was reduced, but $80 \%$ overlap was taken into account.

\begin{tabular}{|l|c|}
\hline \multicolumn{1}{|c|}{ Parameter } & Value \\
\hline Sensor size & $35.9 \mathrm{~mm} \times 23.9 \mathrm{~mm}$ \\
Number of pixels & $8256 \times 5504$ \\
Pixel size & $0.0044 \mathrm{~mm}$ \\
Focal length & $24 \mathrm{~mm}$ \\
\hline
\end{tabular}

Table 1. Specifications DSLR Nikon D850.

The three objects were each recorded from both sides, above and below. For each side of the object, images were taken at a distance of approx. $100 \mathrm{~cm}$ from three different heights. An example of the closed-loop arrangement taken from one side of an object with approx. 150 images is shown in Figure 5 (top). The resolution in object space (GSD) is approx. $0.22 \mathrm{~mm}$. According 
to Nyquist-Shannon sampling theorem, the resolution was more than doubled to guarantee the defined resolution of $0.5 \mathrm{~mm}$ (Luhmann et al., 2019, p. 149). Furthermore, detailed images were taken at complex object areas that are particularly occluded, shadowed or finely structured with an acquisition distance of 30 $\mathrm{cm}$ and an object resolution of approx. $0.04 \mathrm{~mm}$. For all image sets, tilted images were also taken to ensure sufficiently accurate camera calibration.

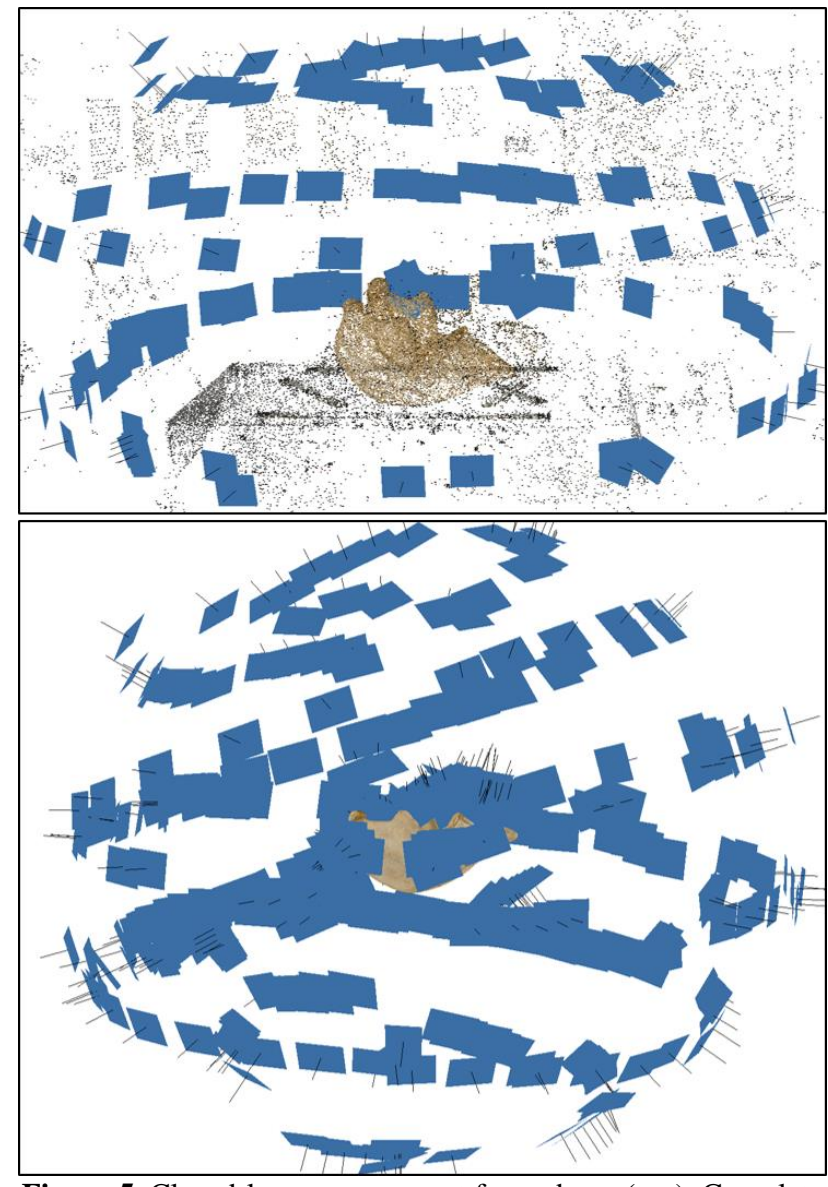

Figure 5. Closed-loop arrangement from above (top). Complete closed-loop arrangement from above and below (bottom).

For the scaling of the scene, two scale bars were placed in object space. In addition, two further scale bars were used as independent reference lengths for verification of the captured image bundle. Figure 5 (bottom) shows a complete all-round configuration of both sides of the object with 377 images. The number of images taken is listed in Table 2.

\begin{tabular}{|l|c|c|}
\hline Dataset & \multicolumn{2}{|c|}{ Number of images } \\
\hline & Images & Detailed images \\
\hline Lower jaw & 274 & 103 \\
Main skull & 555 & 197 \\
Upper skull & 352 & 86 \\
\hline
\end{tabular}

Table 2. Total number of images for data acquisition.

\subsection{Hand-held 3D scanning system}

A hand-held 3D scanning system, Creaform GO!Scan, was used as second method. The specifications of the hand-held scanner are listed in Table 3. Basically, the data acquisition was carried out under the same external conditions as before. The object is recorded from one side, and then the object is rotated and recorded from the other side.

Due to the sensitive object surface, no attached reference targets can be used. This would be necessary to scan with the highest possible resolution of $0.2 \mathrm{~mm}$. However, a resolution of $0.5 \mathrm{~mm}$ is used to meet the desired specifications. The registration of the point cloud is determined by geometric features of the object. Since the resolution is verified by the manufacturer, it is not necessary to scan at twice the resolution as it has been done for SfM data acquisition. The hand-held system was moved slowly and evenly over the object. Before data acquisition, the hand-held scanner is calibrated using a flat test field provided by the manufacturer.

\begin{tabular}{|l|c|}
\hline \multicolumn{1}{|c|}{ Parameter } & Value \\
\hline Accuracy & $0.05 \mathrm{~mm}$ \\
\hline Volumetric accuracy & $0.05 \mathrm{~mm}+0.15 \mathrm{~mm} / \mathrm{m}$ \\
\hline Resolution & $0.1 \mathrm{~mm}$ \\
\hline Mesh resolution & $\begin{array}{c}0.2 \mathrm{~mm} \text { (positioning via } \\
\text { targets) }\end{array}$ \\
\hline & $\begin{array}{c}0.5 \mathrm{~mm} \text { (positioning via } \\
\text { geometry) }\end{array}$ \\
\hline Object size & $0.1-4 \mathrm{~m}$ \\
\hline
\end{tabular}

Table 3. Specifications for hand-held 3D scanning system Creaform GO!Scan.

\section{DATA PROCESSING}

The data was processed at the Institute for Applied Photogrammetry and Geoinformatics (IAPG) in Oldenburg, Germany. A PC with 256 GB RAM and GeForce RTX 3090 (24 GB) was used.

\subsection{Data processing SfM}

The photogrammetric evaluation was carried out with the SfM software Agisoft Metashape (version 1.7.2). For all objects, the calculations were made in the same way and with the highest quality settings. The evaluation procedure is shown schematically in Figure 6.

\begin{tabular}{|l|l|l|l|}
\hline $\begin{array}{l}\text { Recorded data } \\
\text { from above }\end{array}$ & $\begin{array}{l}\text { Image } \\
\text { orientation }\end{array}$ & $\begin{array}{l}\text { Calculation of } \\
\text { rough pointcloud }\end{array}$ \\
\hline $\begin{array}{l}\text { Recorded data } \\
\text { from below }\end{array}$ & Orientation of all images \\
\hline
\end{tabular}

Figure 6. Processing workflow in Agisoft Metashape.

In order to be able to evaluate all images of an object together, i.e. front and back, the images must be masked. First, the images of one data set are oriented and a sparse point cloud is calculated. The area of interest is defined and the images are masked by transformation from object space to image space. The masked images and the unmasked images from the second data set can be orientated together. Subsequently, it is possible to calculate a point cloud. In the final mesh, all images can be used as basis for texturing. The unmasked images contain scaling information that are taken into account in the bundle adjustment. Two cameras, one for close-range images and one for detailed images, are calibrated separately. The result is a textured meshed 3D model as shown in Figure 7. Table 4 shows quality parameters of the bundle adjustment. For the main skull, the average reprojection error (RMS) is 0.9 px. From this, a mean precision of the object coordinates of $0.20 \mathrm{~mm}$ can be derived. The independent reference distances also allow for checking the external accuracy of reconstruction. For the main skull, the average deviation of the reference distances is $0.025 \mathrm{~mm}$. As Table 4 shows, the average 
deviation of the reference is in the same order of magnitude for the other objects. Examination of the references makes it clear that the parameters of the bundle adjustment are within the expected accuracy range.

\begin{tabular}{|l|c|c|c|}
\hline \multicolumn{1}{|c|}{ Object } & $\begin{array}{c}\text { RMS } \\
(\mathrm{px})\end{array}$ & $\begin{array}{c}\text { RMS } \\
(\mathrm{mm})\end{array}$ & $\begin{array}{c}\text { Average deviation of } \\
\text { reference }(\mathrm{mm})\end{array}$ \\
\hline Jaw & 0.7 & 0.19 & 0.018 \\
Main skull & 0.9 & 0.20 & 0.025 \\
Upper skull & 0.8 & 0.19 & 0.029 \\
\hline
\end{tabular}

Table 4. Quality parameters of bundle adjustment.
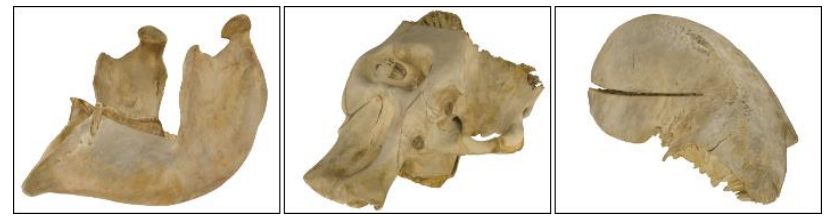

Figure 7. Textured and meshed 3D model from SfM.

\subsection{Data processing hand-held scanner}

The evaluation of the hand-held 3D scanning data is done with the software programs VXelements (version 8.1.1) and VXmodel (version 8.1.1) that are provided by the manufacturer Creaform. In VXelements, the data acquisition and cleaning of the raw data is carried out.

\begin{tabular}{|c|c|c|c|}
\hline \multirow{2}{*}{$\begin{array}{l}\text { Recorded data } \\
\text { from above }\end{array}$} & \multirow{2}{*}{$\begin{array}{l}\text { Textured 3D- } \\
\text { mesh }\end{array}$} & & \multirow{3}{*}{$\begin{array}{l}\text { Calculation of a } \\
\text { textured mesh of } \\
\text { complet object }\end{array}$} \\
\hline & & \multirow{2}{*}{$\begin{array}{l}\text { Transformation (ICP) } \\
\text { in common object } \\
\text { coordinate system }\end{array}$} & \\
\hline \multirow{2}{*}{$\begin{array}{l}\text { Recorded data } \\
\text { from below }\end{array}$} & \multirow{2}{*}{$\begin{array}{l}\text { Textured 3D- } \\
\text { mesh }\end{array}$} & & \\
\hline & & & \\
\hline
\end{tabular}

Figure 8. Processing workflow with VXelements.

Figure 8 gives a coarse overview of the processing workflow. The processing from above and below of the object is carried out separately in VXelements at first. After the models have been cleaned for outliers, a geometric resolution of $0.5 \mathrm{~mm}$ and the resolution of the texture of $100 \mathrm{dpi}$ were defined. The two models, including the raw data, are further processed in VXmodel. By means of a manual pre-orientation via control points, the transformation into a common object coordinate system is carried out via ICP. It is very important to have sufficient object overlaps for the transformation. With the help of the raw data (images), the texture is completely recalculated for the whole object. At this point it should be mentioned that for the main skull no texture calculation is possible at a geometric resolution of $0.5 \mathrm{~mm}$ and $100 \mathrm{dpi}$, although the used computer corresponds to the recommended computing power of the manufacturer. Finally, the models for upper skull and jaw are available with a geometric resolution of $0.5 \mathrm{~mm}$ and a texture resolution of 100 dpi (see Figure 9). The geometric resolution of the main skull had to be reduced to $0.7 \mathrm{~mm}$ to ensure a texture resolution of $100 \mathrm{dpi}$. The problem of computing power should be addressed to further investigations. Nevertheless, the raw data are available and a non-textured model with a spatial resolution of $0.5 \mathrm{~mm}$ can be calculated.
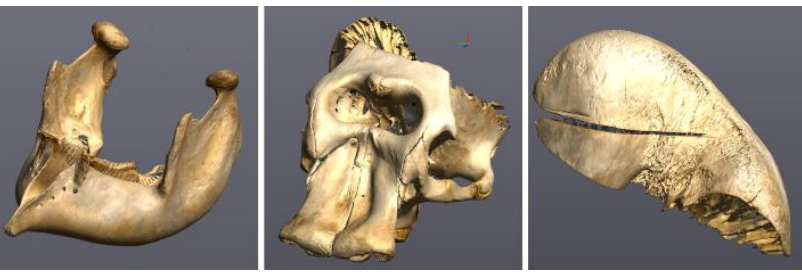

Figure 9. Textured and meshed 3D model from hand-held 3D scanner.

\subsection{Colour calibration}

To calibrate the image colour with the ColorChecker Digital SG, the software ColorChecker Camera Calibration (v2.1.0) is usually applied. The aim is to extract the colour chart from the image to calculate a colour correction matrix (CCM) with the help of the reference colour values calibrated by the manufacturer. With the CCM, the colour values of all pixels can be corrected.

Unfortunately, the software can only process RAW image data. This is not a problem for the SfM data, as it was recorded in RAW format. Since the hand scanner does not allow access to raw data, the colour values of the colour chart have to be extracted from the texture image (bitmap) of the mesh. The procedure for colour calibration has been done as follows.

First the reference colour values of the ColorChecker (CIELab) and the recorded colour values from the texture (sRGB) are needed. Afterwards, the colour space conversion is carried out. The recorded colour values are converted from sRGB to linear RGB, then to CIEXYZ and finally to CIELab. Now the colour correlation matrix (CCM) can be determined according to Wolf (2003). The CCM is calculated as an iterative least-squares solution with a cost function which minimizes the weight of outliers in the fit.

The Euclidean distance between the reference colour values and the recorded colour values is minimised iteratively. With the help of the CMM, the colour values of the whole image can be corrected. Finally, CIELab is transformed back into sRGB colour space. The texture of the hand-held scanner model is now colour calibrated.

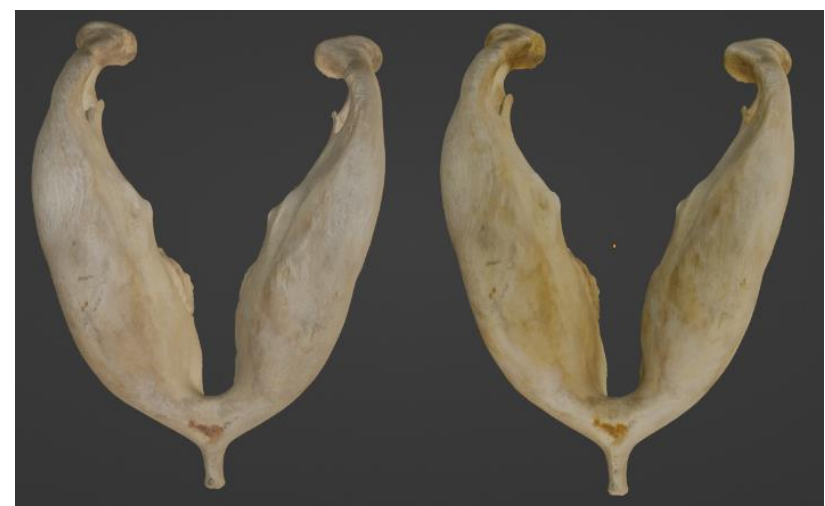

Figure 10. Colour calibrated models of the hand held 3D scanner (left) and SfM (right).

Figure 10 shows the colour calibrated jaw models of the two methods. Even though the texture is very similar, minor differences can be seen. The processing approach was checked with the commercial software, so that no errors can be assumed here. The differences are probably due to the recording conditions with the hand scanner. Since the model appears slightly brighter, it is possible that the scanner was overexposed. In general, the brightness of the images plays an important role. Molada-Tebar et al. (2019) present an approach to bring images to a similar brightness level, which may help with models here as 
well. Schierbaum (2022) is also investigating this topic based on this case study.

\section{COMPARISON OF THE RESULTS}

As already shown, the object parts of the skull could be successfully reconstructed as a textured and meshed 3D model. In the following, the completeness of the models is discussed first. Subsequently, a geometric comparison of the two models is carried out. Finally, the two methods are compared in general.

\subsection{Visual comparison of 3D models}

Even though the final models have already been shown, some details will be discussed here. The models were displayed in different software, which have an influence on the representation of the texture here.
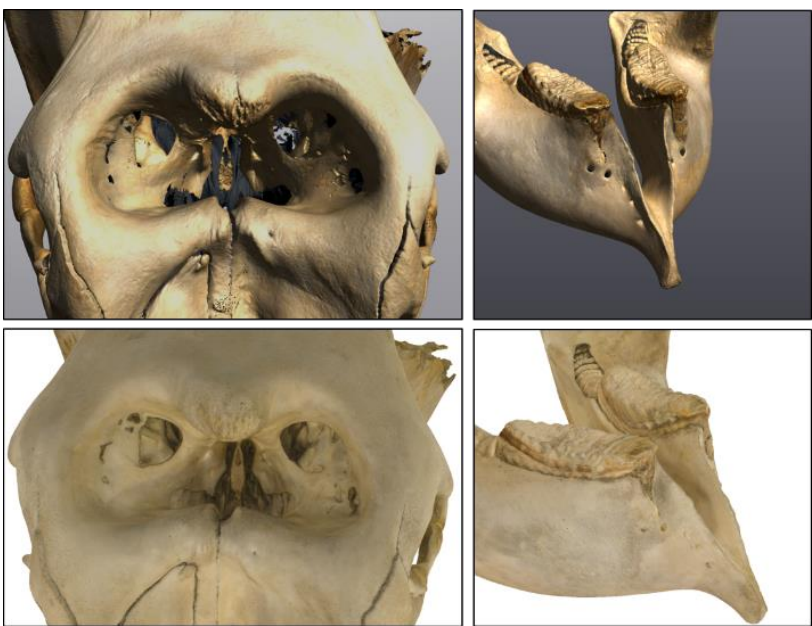

Figure 11. Detailed view of the skull recorded with hand-held scanner (top) and SfM (bottom).

Figure 11 shows the detailed view of the skull. It is clear that the object surface could be completely reconstructed on a high level of detail. The models are both of high quality. Nevertheless, one advantage of SfM becomes clear. Due to the possibility to choose short baselines, deeper object areas (e.g. hole of the elephant trunk) can be reconstructed. The baseline and the angle of view of the cameras of the hand-held scanner are fixed. The object area to be reconstructed must always be observed with both cameras simultaneously, which is not always possible. However, in very deep holes both methods reach their limits. Here, further investigations would be interesting. It might be useful to use a miniature camera or endoscope for macro photogrammetry.

Thanks to the camera-fixed illumination, the hand-held scanner can present a shadow-free object surface. With the help of a camera-fixed ring light, the DSLR images could also be taken without shadows.

\subsection{Geometric comparison of 3D-models}

After the visual inspection of the meshed 3D model is convincing for both SfM and the hand-held scanner, a geometric comparison is aimed. It should be noted that only a relative comparison between the methods can be conducted here. For an absolute comparison, an independent and high accurate reference model should be available. The certified parameters of the hand scanner regarding resolution and accuracy have to suffice as ground truth at this point (see section 2.2, Table 3). The geometric comparison of the models is carried out in the software CloudCompare. The models are roughly pre-oriented using control points and then transformed into a common coordinate system via ICP. Figure 12 shows the cloud-to-mesh comparison of the jaw. The average deviation is $-0.17 \mathrm{~mm}$. As expected, further small deviations occur especially in more complex object areas. In the jaw, for example, positive as well as negative deviations can be found in the complex area of the teeth. The deviations are in a similar range for all objects (main skull $-0.035 \mathrm{~mm}$, upper skull 0.052 $\mathrm{mm})$. The deviations are extremely low and lie within the expected measurement accuracy of SfM. It shows that both methods are at a similar level of accuracy.
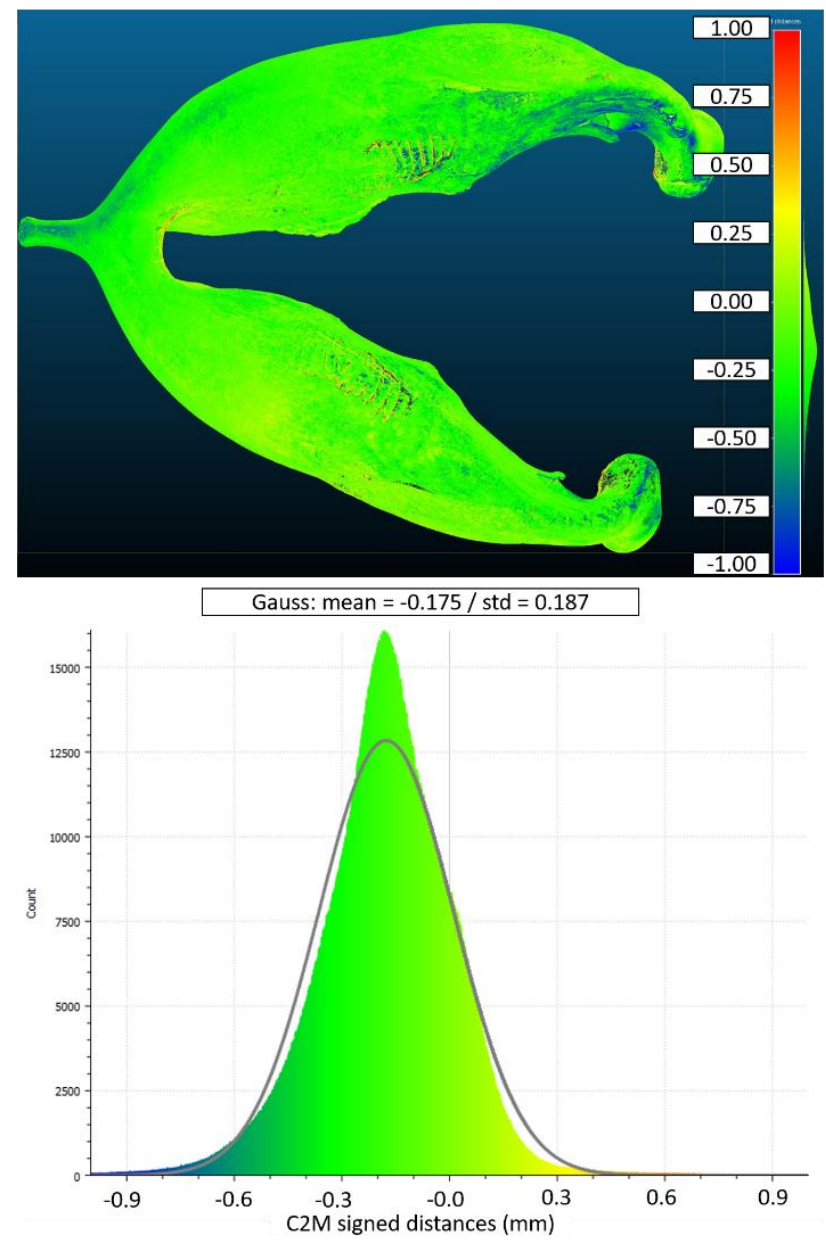

Figure 12. Cloud (SfM) to mesh (hand-held scanner) distances in $\mathrm{mm}$ and corresponding histogram.

\subsection{Comparison of the usage properties}

After comparing the final product of the two methods and finding only minor differences, some general information is discussed.

\begin{tabular}{|l|c|c|}
\hline \multicolumn{1}{|c|}{ Procedure } & SfM & Hand-held scanner \\
\hline Setup & $0.5 \mathrm{~h}$ & $0.5 \mathrm{~h}$ \\
Data acquisition & $1 \mathrm{~h}$ & $1 \mathrm{~h}$ \\
Post-processing & $10.5 \mathrm{~h}$ & $1.5 \mathrm{~h}$ \\
\hline Total time & $12 \mathrm{~h}$ & $3 \mathrm{~h}$ \\
\hline
\end{tabular}

Table 5. Procedure and time required for both methods.

Table 5 summarises the procedure steps and the approximate time required. Even though the same PC with high computing power was used, it should be mentioned that the computing time for the SfM evaluation with Agisoft Metashape can probably still be reduced. Nevertheless, at this point we can speak of a clear 
speed advantage for the hand-held 3D scanning system. While the setup and data acquisition take about the same time with both methods, the post-processing in Agisoft consumes significantly more time. In particular, it is consistently necessary for a user to manually start new processes. With the hand scanner, much less interaction is required. Luhmann et al. (2019) were able to generate models significantly faster using the Reality Capture software than with AgiSoft Metashape. It becomes clear that the applied software plays a decisive role.

\begin{tabular}{|l|l|}
\hline \multicolumn{2}{|c|}{ SfM } \\
\hline \multicolumn{1}{|c|}{ Pros } & \multicolumn{1}{c|}{ Cons } \\
\hline Less expensive & \multicolumn{1}{c|}{ Scale required } \\
\hline $\begin{array}{l}\text { Wide range of resolutions \& } \\
\text { object sizes }\end{array}$ & No visual control during \\
\hline $\begin{array}{l}\text { Flexibility in baselines and } \\
\text { viewing angels }\end{array}$ & Experience in camera use \\
\hline $\begin{array}{l}\text { Access to raw data (e.g. } \\
\text { images) }\end{array}$ & $\begin{array}{l}\text { No manufacturer-guaranteed } \\
\text { 3D accuracy }\end{array}$ \\
\hline
\end{tabular}

Table 6. Advantages and disadvantages of SfM.

\begin{tabular}{|l|l|}
\hline \multicolumn{2}{|c|}{ Hand-held 3D scanning system } \\
\hline \multicolumn{1}{|c|}{ Pros } & \multicolumn{1}{c|}{ Cons } \\
\hline No external lighting required & More expensive \\
\hline $\begin{array}{l}\text { Visual real-time control } \\
\text { during recording }\end{array}$ & $\begin{array}{l}\text { Limited resolution \& } \\
\text { object size }\end{array}$ \\
\hline $\begin{array}{l}\text { Very user-friendly, easy to } \\
\text { handle }\end{array}$ & No access to raw data \\
\hline Fast data processing & \\
\hline
\end{tabular}

Table 7. Advantages and disadvantages of hand-held 3D scanning system.

The advantages and disadvantages of the methods are listed in Tables 6 and 7. Basically, the use of SfM is cheaper However, SfM requires much more user experience, especially in handling cameras and image acquisition. Furthermore, high-quality scale bars are needed to scale the model. For professionals, it is advantageous that the images (raw data) can be accessed. The biggest advantage is the flexibility. A high range of resolution and object size is possible, as well as the simple adaption of baselines and viewing angels, which is helpful for complex objects.

The biggest advantage of the hand-held scanning system GO!Scan is its user-friendliness. The device and the software are easy to use and the data can already be checked for completeness during the recording in real-time. A rough textured and meshed $3 \mathrm{D}$ model is available immediately after recording. The disadvantage is that there is no access to the raw data such as the recorded images. Furthermore, the range of resolution and object size is clearly defined and cannot be changed, which leads to less flexibility. For the quick recording and modelling of objects of similar size, the hand scanner is highly recommended due to its ease of use and high quality.

\section{SUMMARY AND OUTLOOK}

In this work, the Goethe Elephant skull was digitised with high accuracy using a hand-held 3D scanning system and Structurefrom-Motion both with a resolution and approx. accuracy of 0.5 $\mathrm{mm}$. The elephant skull can be defined as a complex object. For a complete capture, the object parts have to be recorded from below and above. Data acquisition and data processing are described in detail for each method. Statistical parameters are used to estimate the quality of the SfM bundle adjustment. Independent reference lengths (scale bars) show a mean deviation of $0.018-0.029 \mathrm{~mm}$. This is within the expected accuracy range for SfM. As the handheld 3D scanning system is verified by the manufacturer, no further investigation of accuracy has been carried out here. Overall, the lower jaw, the main skull and the upper skull are available as a textured meshed 3D model. Due to the camera-fixed illumination of the scanner and on the camera, both complex and trivial object areas could be captured completely and shadow-free. The desired spatial resolution of 0.5 $\mathrm{mm}$ was achieved for all models. However, the software VXelements (Creaform) was not able to texture the main skull at highest resolution. Despite the high-end notebook, a textured model can currently only be created with a geometric resolution of $0.7 \mathrm{~mm}$.

In addition, the colour values of the texture were calibrated with the help of the ColorChecker Digital SG. Nevertheless, small visual differences could be observed when comparing the colour calibrated models from SfM and hand-held scanner. A slight overexposure of the hand-held scanner is suspected. Alternatively, the brightness level of the images/models leads to the differences. Nevertheless, a method was shown to colour calibrate hand-held scanner models. In respect of the importance of colour authenticity for cultural objects, more research is needed here.

Furthermore, the 3D models of the two methods were compared. Visually, there are hardly any differences. SfM has a little advantage recording holes. The baselines and viewing angels can be individually adjusted here. Nevertheless, the skull contains deep holes that have to be recorded with a miniature camera using macro photogrammetry. This could be part of further investigations.

A relative spatial comparison of the models shows average deviations of -0.035 to $-0.175 \mathrm{~mm}$, depending on the model. These small deviations show that the models are geometrically at a similar level of accuracy. With both methods it is possible to digitise cultural objects with high accuracy. In the future, an absolute comparison using a high accuracy measured reference object would be of high interest. Combined measurements and data fusion?

In addition, noted usage properties of the two methods were defined and compared as advantages and disadvantages. The main advantage of SfM is the purchase price and flexibility with object size and resolution. The main advantage of the hand scanner is the very simple operation. Even inexperienced persons can quickly carry out a 3D recording, and the visual real-time impression of the model is a major advantage. It should be noted that the comparison does not apply to the high number of handheld scanners available.

The final 3D models will be used for museum purposes, such as virtual presentations and 3D printings.

\section{REFERENCES}

Barszcz, M., Montusiewicz, J., Paśnikowska-Łukaszuk, M., Sałamacha, A., 2021. Comparative analysis of digital models of objects of cultural heritage obtained by the "3D SLS" and "SfM" methods. Applied Sciences 11 (12), 5321.

Fau, M., Cornette, R., Houssaye, A., 2016. Photogrammetry for 3D digitizing bones of mounted skeletons: Potential and limits. Comptes Rendus Palevol 15 (8), 968-977. 
FADGI, 2016. Federal Agencies Digital Guidelines Initiative. Technical Guidelines for Digitizing Cultural Heritage Materials: Creation of Raster Image Files.

Kersten, T. P., Lindstaedt, M., Starosta, D., 2018. Comparative geometrical accuracy investigations of hand-held 3D scanning systems - an update. Int. Arch. Photogramm. Remote Sens. Spatial Inf. Sci. XLII-2, 487-494.

Lachat, E., Landes, T., Grussenmeyer, P., 2017. Performance investigation of a handheld 3D scanner to define good practices for small artefact 3D modeling. Int. Arch. Photogramm. Remote Sens. Spatial Inf. Sci. XLII-2/W5, 427-434.

De Luca, D., Del Giudice, M., Grasso, N., Matrone, F., Osello, A., Piras, M., 2019. Handheld volumetric scanner for 3D printed integrations of historical elements: comparison and results. Int. Arch. Photogramm. Remote Sens. Spatial Inf. Sci. XLII-2/W15, 381-388.

Luhmann, T., Chizhova, M., Gorkovchuk, D., Hastedt, H., Chachava, N., Lekveishvili, N., 2019. Combination of terrestrial laserscanning, UAV and close-range photogrammetry for 3D reconstruction of complex churches in Georgia. Int. Arch. Photogramm. Remote Sens. Spatial Inf. Sci. XLII-2/W11, 753761.

Luhmann, T., Boehm, J., Kyle, S., Robson, S., 2019. CloseRange Photogrammetry and 3D Imaging. 3rd revised and expanded edition. Berlin, Boston: de Gruyter.

Matuschek, O., 2020. Goethes Elefanten. Erste Auflage. Berlin: Insel Verlag (Insel-Bücherei, 1489).

Molada-Tebar, A., Marqués-Mateu, Á., Lerma, J. L., 2019. Correct use of color for cultural heritage documentation. ISPRS Ann. Photogramm. Remote Sens. Spatial Inf. Sci. IV-2/W6, 107113.

Nietiedt, S., Kalinowski, P., Hastedt, H., Luhmann, T., 2020. Accuracy investigations of image matching techniques by means of a textured dumbbell artefact. Int. Arch. Photogramm. Remote Sens. Spatial Inf. Sci. XLIII-B2-2020, 791-796.

Stylianidis, E., Remondino, F. (eds.), 2016. 3D Recording, Documentation and Management of Cultural Heritage. Whittles Publishing, Caithness, UK.

Santos, P., Ritz, M., Tausch, R., Schmedt, H., Monroy, R., De Stefano, A., Posniak, O., Fuhrmann C., Fellner, D. W., 2014. CultLab3D - On the verge of 3D mass digitization. GCH '14: Proceedings of the Eurographics Workshop on Graphics and Cultural Heritage, 65-73.

Schierbaum, A., 2022. Untersuchungen zur Farbkalibrierung von texturierten Oberflächenmodellen am Beispiel des Goethe Elefantenschädels. Bachelor thesis (unpublished). Jade Hochschule, Oldenburg.

Van Dormolen, H., 2012. Metamorfoze Preservation Imaging Guidelines - Image quality. National Archives of the Netherlands, The Hague, NL.

Wenzel, K., Rothermel, M., Fritsch, D., Haala, N., 2013. Image acquisition and model selection for multi-view stereo. Int. Arch. Photogramm. Remote Sens. Spatial Inf. Sci. XL-5/W1, S. 251258. DOI: 10.5194/isprsarchives-XL-5-W1-251-2013.

Wolf, S., 2003. Color Correction Matrix for Digital Still and Video Imaging Systems. NTIA Technical Memorandum TM-04406. U.S. Department of Commerce, USA. 